\title{
Prótesis total de fémur en un paciente con quiste óseo hidatídico complicado. Reporte de un caso
}

\author{
Federico Minoru Isobe, Horacio A. Caviglia, Alexis Eljatib, Jorge Vargas Gonzales, Juan Manuel Lovera \\ División de Ortopedia y Traumatología, Hospital General de Agudos “Dr. Juan A. Fernández”, Ciudad Autónoma \\ de Buenos Aires, Argentina
}

\section{RESUMEN}

Se presenta un caso de un hombre de 31 años con fractura de fémur. Los estudios complementarios mostraron una imagen compatible con lesión quística. El primer estudio por biopsia de dicho quiste informó erróneamente un quiste simple. Se realizó una osteosíntesis con enclavado endomedular. El paciente tuvo una evolución tórpida asociada a imágenes líticas diafisarias y pérdida de la reducción de la fractura. Se retiró el material y se tomaron muestras del canal endomedular, cuyo cultivo reveló Pseudomonas aeruginosa y restos de quistes hidatídicos en la anatomía patológica. En nuestro centro, fue tratado por una seudoartrosis infectada secundaria a un quiste óseo hidatídico complicado. Se le colocó un megaespaciador de cemento con antibiótico y, luego, una prótesis total de fémur como tratamiento definitivo. El compromiso óseo es muy raro y de difícil diagnóstico, y puede llevar a una diseminación severa. Si bien no hay consenso ni tratamiento de elección para los casos graves, el reemplazo femoral total en dos tiempos representa una opción alentadora para conservar el miembro, con resultados satisfactorios a corto y mediano plazo. Palabras clave: Quiste hidatídico complicado; megaprótesis de cadera; seudoartrosis infectada.

Nivel de Evidencia: IV

Total femoral replacement in patient with complicated bone hydatid cyst. Case report

\section{ABSTRACT}

We report the case of a 31-year-old male patient presenting a femoral fracture whose complementary studies revealed an image consistent with a cystic lesion. The first biopsy study of this cyst erroneously reported a simple cyst. Osteosynthesis with intramedullary nailing was performed. The patient had a poor postoperative course associated with diaphyseal osteolytic images and loss of fracture reduction. The material was removed and intramedullary canal specimens were taken, which were positive for Pseudomonas aeruginosa and revealed remains of hydatid cysts through pathologic examination. The patient was referred to our center for the treatment of an infected pseudarthrosis secondary to a complicated hydatid bone cyst. A two-stage procedure was performed. The first stage involved the placement of an antibiotic-impregnated cement mega-spacer and the second stage involved the implantation of a total femur prosthesis as definitive treatment. The bone hydatidosis involves a challenging diagnosis, is very rare, and can cause severe dissemination. While there is no consensus or gold standard treatment for severe cases, twostage total femoral replacement represents an encouraging option for limb preservation, showing satisfactory short- and mediumterm outcomes.

Key words: Complicated hydatid cyst; hip mega-prosthesis; infected pseudarthrosis.

Level of Evidence: IV

\section{INTRODUCCIÓN}

La hidatidosis o equinococosis quística es una zoonosis causada por el estadio larvario del cestodo Echinococcus granulosus, responsable de una importante morbilidad y mortalidad en áreas endémicas de países mediterráneos, Asia, África y América Latina. ${ }^{1}$ Los huéspedes definitivos son el perro doméstico y otros cánidos silvestres, como lobos o chacales, en los que se desarrolla la forma adulta; y los huéspedes intermediarios son principalmente los ovinos, pero también, los caprinos, los cerdos, los bovinos, los guanacos, etc., en los cuales se desarrolla la forma

Recibido el 7-12-2019. Aceptado luego de la evaluación el 12-12-2019 • Dr. FEDERICO MINORU ISOBE • federicominoruisobe @ gmail.com 
o fase larvaria, o metacestodo. El humano resulta ser un huésped accidental en el ciclo del parásito, sobre todo, en zonas rurales de producción ganadera, en especial, ovina y caprina, con infraestructura sanitaria deficiente (sin salas de faena, redes de agua potable, pozos para la eliminación de vísceras, etc.), escaso conocimiento de la enfermedad y una población canina sin atención veterinaria adecuada. ${ }^{2}$

La hidatidosis ósea es poco frecuente y, según su localización y el tiempo de evolución, se la suele diagnosticar por sus complicaciones, como déficit neurológico por compresión medular en casos de localización vertebral, fractura patológica en huesos largos o fistulización e infección secundaria en estadios avanzados con compromiso de partes blandas.,

El objetivo de este artículo es comunicar un caso clínico de quiste hidatídico óseo de fémur complicado, asociado a osteomielitis e infección de piel y partes blandas, tratado con una megaprótesis de fémur total en dos tiempos, y un seguimiento evolutivo de dos años.

\section{CASO CLÍNICO}

Hombre de 31 años con antecedente de fractura de fémur derecho por caída de altura, durante la actividad agraria en el ámbito rural, que fue tratado con enclavado endomedular. En el estudio de una biopsia por punción previa de una lesión quística hallada en las imágenes radiográficas, en el mismo hueso, a nivel de la fractura, se halló un quiste óseo simple.

La evolución posoperatoria a corto plazo fue mala, con osteosíntesis fallida asociada a imágenes heterogéneas y líticas difusas a nivel diafisario (Figura 1).

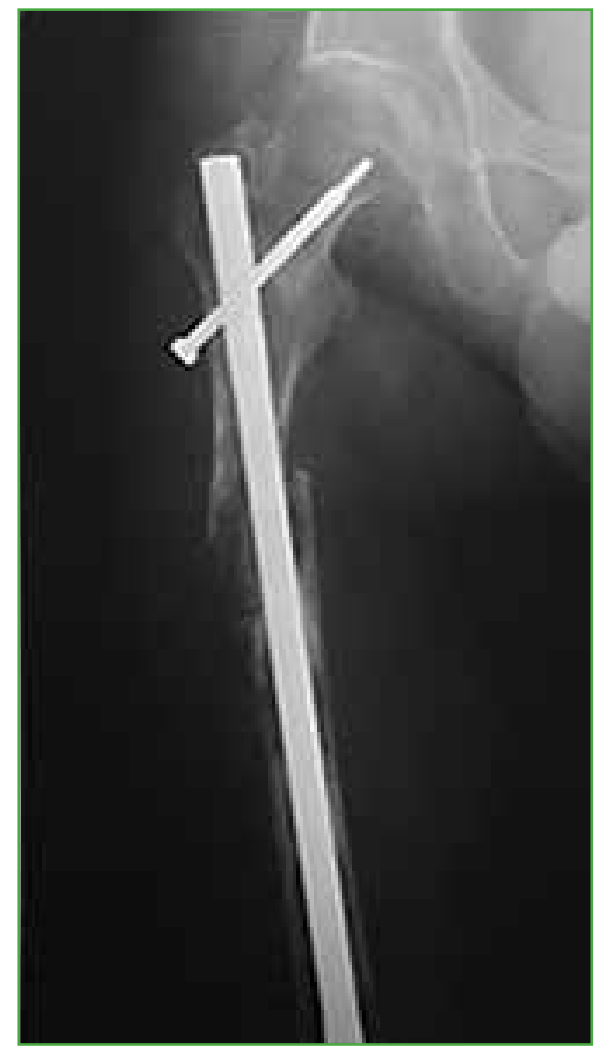

Figura 1. Evolución radiográfica de la primera intervención quirúrgica. 
Se retiró el material y se realizó una fijación con tutor externo. Se obtuvieron nuevas muestras, que fueron positivas para Pseudomonas aeruginosa en partes blandas y hueso. En el estudio anatomopatológico, se observaron varios fragmentos de pared fibrohialina compatibles con pared adventicia de quiste hidatídico sin parásitos vivos, posiblemente por el fresado del enclavado endomedular.

La evolución de las partes blandas siguió siendo mala, con fístulas activas y se retiró el tutor externo. Posteriormente el paciente fue derivado a nuestro centro con diagnóstico de seudoartrosis infectada de fémur derecho en el contexto de un quiste hidatídico complicado.

Se obtuvieron nuevas radiografías y se realizó una tomografía computarizada que mostró imágenes heterogéneas compatibles con pandiafisitis femoral y seudoartrosis en su tercio proximal. La resonancia magnética reveló imágenes hipointensas pandiafisarias en T1, de patrón moteado, con compromiso cortical generalizado, que respetaba cóndilos y la cabeza femoral; imágenes hiperintensas en T2 tanto de hueso como de partes blandas, acordes al proceso infeccioso agregado (Figura 2).

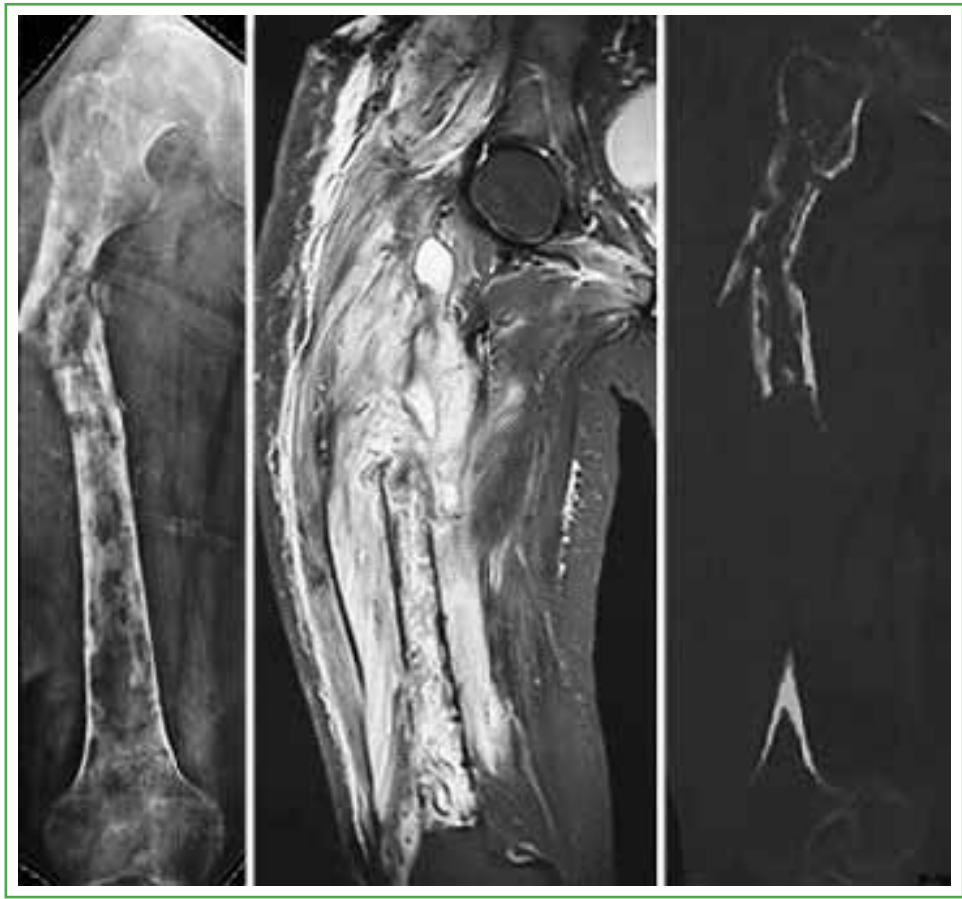

Figura 2. Estudios por imágenes del muslo derecho.

Se realizó una limpieza quirúrgica con toma de muestras, que resultaron todas positivas para Pseudomonas aeruginosa en partes blandas y hueso. En consecuencia, se inició un tratamiento antibiótico dirigido con piperacilina/ tazobactam; además, se confirmó la presencia de restos de quiste hidatídico en un nuevo estudio anatomopatológico. Luego de la mejoría de las partes blandas y de los parámetros bioquímicos, se efectuó la resección femoral total y la colocación de un megaespaciador de cemento, articulado y modular con gentamicina (Figura 3). 


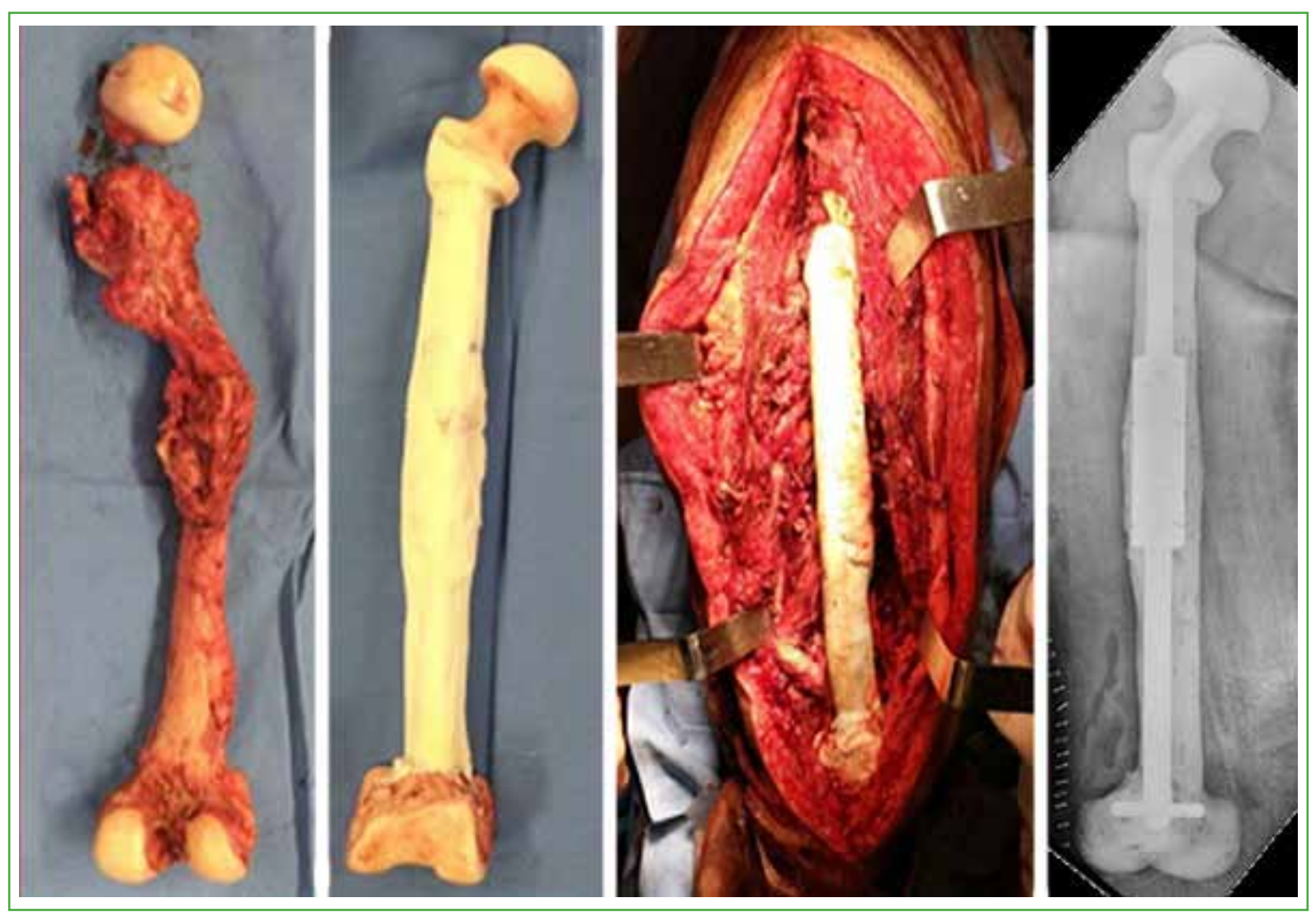

Figura 3. Resección femoral y colocación de megaespaciador de cemento con antibiótico.

A los tres meses y ante la evolución infectológica favorable, se procedió al tratamiento definitivo: retiro del espaciador de cemento y colocación de una megaprótesis para el reemplazo femoral total con abordaje posterolateral extendido hasta la tuberosidad anterior de la tibia y con reparo del abanico glúteo al componente metafisario de la prótesis (Figura 4). El paciente fue tratado con albendazol por 28 días, después de la cirugía. Durante siete meses, los parámetros inflamatorios se mantuvieron normales, sin eosinofilia y la evolución de partes blandas fue buena.

El paciente fue dado de alta con la herida cicatrizada y tratamiento kinesiológico progresivo.

Luego de la cirugía definitiva, la evolución tanto clínica como funcional fue favorable. Al año del procedimiento, los rangos de movilidad pasiva eran: en la cadera derecha: flexión $90^{\circ}$, extensión $0^{\circ}$, abducción $25^{\circ}$, aducción $15^{\circ}$, rotación interna $10^{\circ}$ y rotación externa $10^{\circ} \mathrm{y}$, en la rodilla derecha, flexión $90^{\circ}$ y extensión completa. No tuvo compromiso vascular ni neurológico posterior. La evolución funcional fue evaluada mediante el puntaje de Harris con un valor posoperatorio del 72,35\% al año y del 80,50\% a los dos años (preoperatorio 19\%). Se observó una marcada recuperación funcional y el nivel de satisfacción del paciente fue alto. 


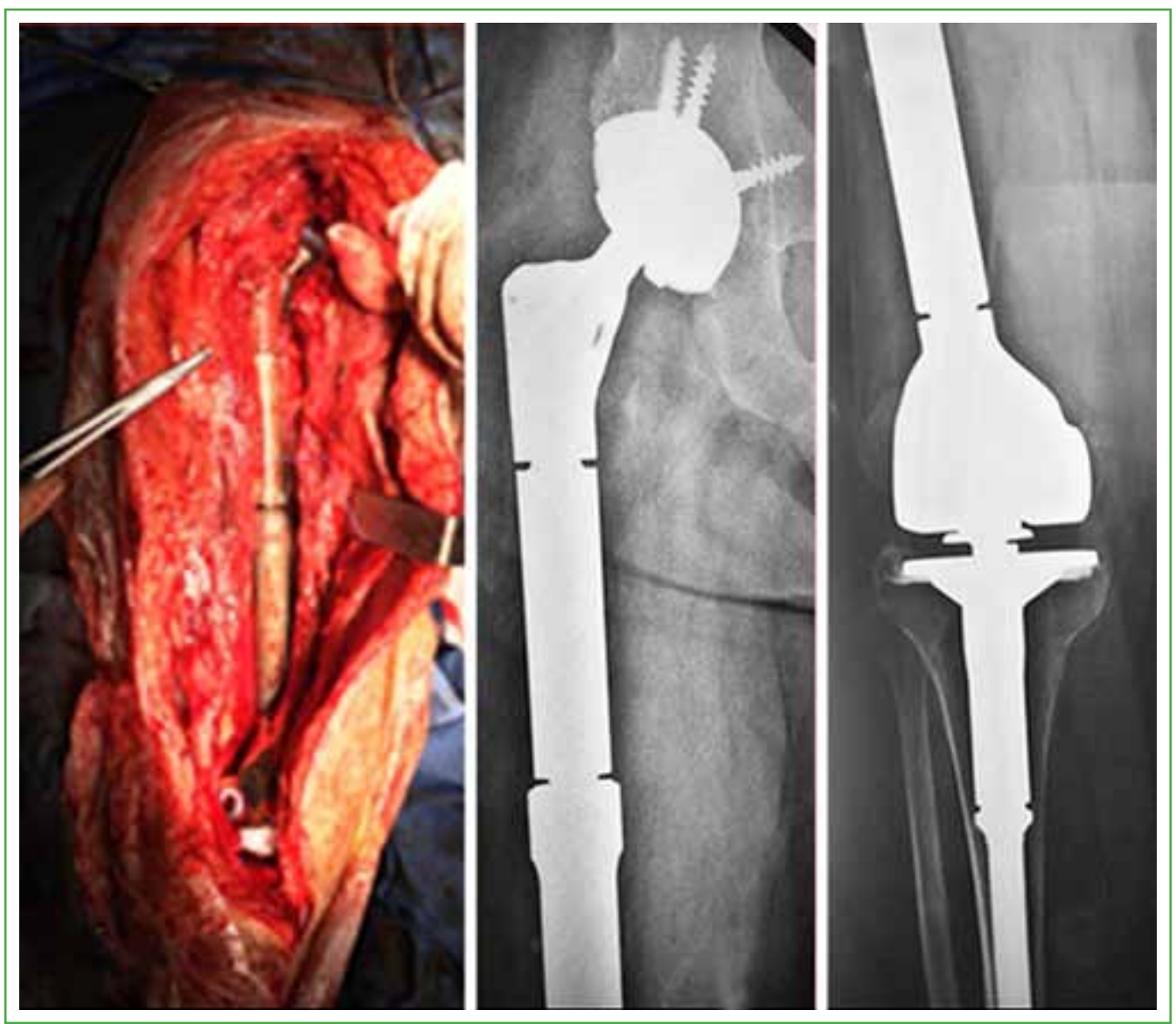

Figura 4. Abordaje posterolateral extendido y control radiográfico posoperatorio.

\section{DISCUSIÓN}

Esta zoonosis representa un importante problema de salud pública en nuestro país, como consecuencia de los costos generados a los servicios de salud por la atención de los pacientes, porque las personas que padecen la enfermedad pueden requerir internaciones prolongadas y su calidad de vida se ve afectada. ${ }^{2}$

Se han caracterizado diversas cepas de Echinococcus granulosus utilizando criterios morfológicos, biológicos, bioquímicos y epidemiológicos. América del Sur registra niveles endémicos en Argentina, Chile, Uruguay, sur de Brasil y las regiones montañosas de Perú y Bolivia. E. vogeli y E. oligarthrus se detectan en Centroamérica y en la zona oeste de América del Sur. ${ }^{5}$

La mayor parte de los casos de hidatidosis en humanos son producidos por la cepa ovina y, en menor medida, por cepas de cérvidos o de ganado vacuno. En la Argentina, durante 2010, se han notificado 385 casos de hidatidosis al Sistema Nacional de Vigilancia de la Salud.

La hidatidosis no se transmite directamente de una persona a otra ni de un huésped intermediario a otro. ${ }^{2} \mathrm{El}$ hombre ingiere accidentalmente los huevos del parásito (eliminado en la materia fecal de los perros) a través de las manos, hábitos de pica, geofagia, ingesta de verduras mal lavadas o por contacto estrecho con el animal. Este es el motivo por el cual la infección es más frecuente en la niñez.

Una vez que los huevos del parásito han ingresado en el organismo, se produce la liberación del embrión hexacanto que atraviesa la mucosa intestinal y pasa a la circulación portal hacia el hígado que se comporta como el primer filtro. Si logra evitar el filtro hepático, puede llegar a los pulmones (segunda localización en frecuencia) y, de allí por la circulación sistémica, al resto del organismo y desarrollar el quiste hidatídico. ${ }^{5}$ 
Las localizaciones más frecuentes de los quistes son: hígado (67-89\%) y pulmón (10-15\%), con menos frecuencia, bazo (1-3\%), riñón (1,5-2\%), peritoneo (3-5\%) y cerebro (2\%) y, con muy poca frecuencia, páncreas, hueso, corazón y órbitas. ${ }^{5}$

La localización ósea es muy poco habitual, tiene una incidencia del 1,4-3\% de los casos..$^{6-8}$ Las lesiones se distribuyen en: columna vertebral (40-50\%), huesos largos (25-30\%) y pelvis (15-20\%), y más raramente en cráneo, esternón, escápula y falanges. ${ }^{910}$ La diseminación ósea se produce por tres mecanismos descritos:

a) Compresión gradual de los tejidos adyacentes, con eventual atrofia y necrosis.

b) Obstrucción vascular de los vasos nutricios que causan isquemia y necrosis ósea.

c) Proliferación de células osteoclásticas alrededor del foco infeccioso de la hidatidosis.

Cualquiera de estos mecanismos o la combinación de ellos causan complicaciones. ${ }^{2}$

Desde este punto de vista, la gran mayoría de los pacientes con compromiso óseo se presenta con un cuadro inespecífico o con las complicaciones, como fracturas patológicas, déficit neurológico cuando afecta la columna vertebral o infecciones sobreagregadas con fístulas activas o sin ellas. ${ }^{1}$

En general, la enfermedad permanece clínicamente silente durante largos períodos, se suele diagnosticar en adultos, aun cuando la infección ocurre antes, en la adolescencia o la niñez. Por esta razón, su diagnóstico se torna dificultoso o se diagnostica cuando las lesiones son extensas y diseminadas, y un porcentaje no menor solo se diagnostica después de la cirugía. ${ }^{3,10}$

El diagnóstico precoz y oportuno es importante, ya que permite controlar y tratar al paciente en forma adecuada. Por ello, es fundamental la sospecha clínica ante la presencia de un tumor quístico. ${ }^{2}$

Los exámenes complementarios son múltiples, pero a nivel óseo, hemos utilizado las imágenes radiográficas, tomográficas y de resonancia magnética, para evaluar el compromiso óseo y de partes blandas, considerando que, en nuestro paciente, se superpuso con una infección severa pandiafisaria. Agregamos una angiorresonancia, aunque no es un estudio de rutina, para determinar la situación de los grandes vasos del miembro afectado.

Entre los análisis de laboratorio, se pueden mencionar los siguientes:

- Método directo: examen en fresco de las piezas quirúrgicas o conservadas en formol (esputo, orina, líquido cefalorraquídeo, vesículas hijas, escólices).

- Método indirecto o serológico:

- Hemaglutinación indirecta

- ELISA (IgG) y Western Blot: tienen una sensibilidad diagnóstica más alta que la hemaglutinación indirecta y son de elección para lograr la confirmación serológica de los casos sospechosos y complicados.

- El Arco 5: ya no se usa para el diagnóstico de hidatidosis. ${ }^{5}$

A pesar de estos métodos, se llega al diagnóstico definitivo mediante el resultado histopatológico de una biopsia por punción o pieza resecada, como ocurrió en nuestro caso. ${ }^{11}$

Como diagnósticos diferenciales se plantean, según la localización y las características de las lesiones: absceso, quiste simple, hemangioma, tuberculosis, entre otros. ${ }^{5}$

En la actualidad, el albendazol es el benzimidazol de elección. Hay varios factores que pueden influir en la respuesta terapéutica, como la edad, y el tamaño y la localización anatómica del quiste. El albendazol se debe administrar a una dosis de 10-15 mg/kg/día, en dos tomas diarias, cada $12 \mathrm{~h}$, luego de una comida con algún contenido graso, ya que mejora la absorción del fármaco. El tiempo mínimo de tratamiento es de tres meses, aunque puede prolongarse hasta seis meses, salvo si hay intolerancia o alteración de los análisis de laboratorio. ${ }^{2}$ El praziquantel también podría ser útil en casos de derrame de contenido del quiste durante la cirugía. También se ha demostrado que el tratamiento combinado con albendazol (10 mg/kg/día) y praziquantel ( $25 \mathrm{mg} / \mathrm{kg} / \mathrm{día})$, administrado durante 30 días, antes de la cirugía, genera más inviabilidad de los protoescólices que la monoterapia, pero se necesitan más estudios para evaluar la real eficacia de este tratamiento combinado. ${ }^{2}$

A pesar de que no existen estudios comparativos directos entre albendazol y cirugía, se considera que la farmacoterapia es una opción secundaria a la cirugía, porque con la opción médica, los quistes desaparecen en no más del $50 \%$ de los pacientes, su tamaño no varía en, al menos, el 20-25\% y cerca del 15-30\% tiene recurrencias durante el seguimiento. ${ }^{12}$

Si bien no hay consenso en cuanto al tipo de resección y la necesidad de adaptarla a las distintas presentaciones, el tratamiento quirúrgico de elección para la hidatidosis ósea es la extirpación completa de la lesión; sin embargo, en la mayoría de los casos, esto no es posible, pues se trata de lesiones difusas y extensas en las cuales la terapia eficaz sería mutilante y dejaría secuelas funcionales importantes. A pesar de su naturaleza parasitaria, hay reportes 
que aconsejan tratar esta enfermedad quirúrgicamente bajo criterios oncológicos por su comportamiento localmente destructivo. ${ }^{10}$

Según la bibliografía, queda claro que el compromiso óseo es poco frecuente, pero por otro lado, existe escasa documentación del compromiso severo del fémur tratado con artroplastia femoral total.

Wirbel y cols. recomiendan tratar la hidatidosis ósea de pelvis y fémur con resecciones radicales y reemplazo de cadera con megaprótesis. En estos posoperatorios, la infección del sitio quirúrgico no es rara después de procedimientos prolongados. ${ }^{13}$

Natarajan y cols. publicaron tres casos de compromiso óseo femoral tratados con megaprótesis,${ }^{14}$ al igual que Moore y cols., en 2015, que comunicaron el primer caso tratado con reemplazo total de fémur por compromiso femoral severo. ${ }^{15}$

\section{CONCLUSIONES}

El diagnóstico preciso es fundamental para evitar decisiones equivocadas, como el fresado y el enclavado endomedular descrito en nuestro caso, que conducen a una diseminación importante de las hidátides y posteriormente a una sobreinfección.

Si bien no hay consenso ni tratamiento de elección en estos casos severos, el reemplazo femoral total o la megaprótesis sigue siendo una opción alentadora para la conservación del miembro, con resultados satisfactorios a corto y mediano plazo.

Conflicto de intereses: Los autores no declaran conflictos de intereses.

\section{BIBLIOGRAFÍA}

1. Song XH, Ding LW, Wen H. Bone hydatid disease. Postgrad Med J 2007;83(982):536-42. https://doi.org/10.1136/pgmj.2007.057166

2. Ministerio de Salud. Enfermedades infecciosas. Hidatidosis. Guía para el Equipo de Salud, Buenos Aires, Argentina; 2012:3-26. Disponible en: http://www.msal.gob.ar/images/stories/epidemiologia/pdf/guia-medica-hidatidosis.pdf

3. Papanikolaou A. Osseous hydatid disease. Trans R Soc Trop Med Hyg 2008;102:233-8. https://doi.org/10.1016/j.trstmh.2007.09.012

4. Kalinova K, Proichev V, Stefanova P, Tokmakova K, Poriazova E. Hydatid bone disease: a case report and review of the literature. J Orthop Surg 2005;13(3):323-5. https://doi.org/10.1177/230949900501300321

5. Bellone L, Melonari P. Enfermedades zoonóticas parasitarias. Hidatidosis. En: Consenso sobre Enfermedades Infecciosas Regionales en la Argentina. Recomendaciones de la Sociedad Argentina de Pediatría - Comité Nacional de Infectología. Buenos Aires: Sociedad Argentina de Pediatría; 2013:8-38.

6. Igarzabal JE. Quiste hidatídico de hueso. En: Nuevo tratado de patología quirúrgica. Buenos Aires: Hachette; 1955:473-86.

7. Paz AJ. Hidatidosis ósea. Rev Asoc Argent Ortop Traumatol 1997;62(1):13-23. https://www.aaot.org.ar/revista/1993_2002/1997/1997_1/620115.pdf

8. Agarwal S, Shah A, Khadi SK, Rooney RJ. Hydatid bone disease of the pelvis: A report of two cases and review of the literature. Clin Orthop 1992;(280):251-5. https://doi.org/10.1097/00003086-199207000-00034

9. Agulló Bonus A, Alcalá-Santaella Oria de Rueda A. Hidatidosis muscular. A propósito de tres casos. Rev Esp Reumatol 2002;29:4-6. https://www.semanticscholar.org/paper/Hidatidosis-muscular-A-prop\%C3\%B3sito-de-tres-casos-Bonus-Rueda/ aa183951efb996352c09f5a9ae224aaaac3f95b1

10. Tomak Y, Dabak N, Gulman B, Karaismailoglu TN, Basoglu T, Incesu L. Hydatid disease of the left femur: a case report. Bull Hosp Jt Dis 2001-2002;60(2):89-93. https://pubmed.ncbi.nlm.nih.gov/12003361/ 
11. Inayat F, Azam S, Baig AS, Nawaz G, Ullah W. Presentation patterns, diagnostic modalities, management strategies, and clinical outcomes in patients with hydatid disease of the pelvic bone: a comparative review of 31 cases. Cureus 2019;11(3):e4178. https://doi.org/10.7759/cureus.41

12. Fica A, Soto A, Slater J, Peralta M, Humeres R, Castro M, et al. Quince años de experiencia clínica con hidatidosis. Rev Chil Infectol 2012;29(2):183-91. https://doi.org/10.4067/S0716-10182012000200011

13. Wirbel RJ, Mues PE, Mutschler WE, Salomon-Looijen M. Hydatid disease of the pelvis and the femur. A case report. Acta Orthop Scand 1995;66(5):440-2. https://doi.org/10.3109/17453679508995582

14. Natarajan MV, Kumar AK, Sivaseelam A, Iyakutty P, Raja M, Rajagopal TS. Using a custom mega prosthesis to treat hydatidosis of bone: a report of 3 cases. J Orthop Surg (Hong Kong) 2002;10(2):203-5. https://doi.org/10.1177/230949900201000216

15. Moore D, Baker KC, Les K. Hydatid disease of the femur treated with a total femoral replacement: a case report. JBJS Case Connect 2015;5(1):e7-5. https://doi.org/10.2106/JBJS.CC.M.00279 